\title{
Cross-Sector Partnerships and the Co-creation of Dynamic Capabilities for Stakeholder Orientation
}

\author{
Domenico Dentoni $^{1} \cdot$ Verena Bitzer $^{1} \cdot$ Stefano Pascucci $^{1}$
}

Published online: 26 June 2015

(c) The Author(s) 2015. This article is published with open access at Springerlink.com

\begin{abstract}
This paper explores the relationship between business experience in cross-sector partnerships (CSPs) and the co-creation of what we refer to as 'dynamic capabilities for stakeholder orientation,' consisting of the four dimensions of (1) sensing, (2) interacting with, (3) learning from and (4) changing based on stakeholders. We argue that the co-creation of dynamic capabilities for stakeholder orientation is crucial for CSPs to create societal impact, as stakeholder-oriented organizations are more suited to deal with "wicked problems," i.e., problems that are large, messy, and complex (Rittel and Webber, Policy Sciences 4:155-169, 1973; Waddock, Paper presented at the 3rd international symposium on cross sector social interactions, 2012). By means of a grounded theory approach of inductive research, we collected and interpreted data on four global agri-food companies which have heterogeneous experience in participating in CSPs. The results of this paper highlight that only companies' capability of interacting with stakeholders continually increases, while their capabilities of sensing, learning from, and changing based on stakeholders first increase and then decrease as companies gain more experience in CSP participation. To a large extent, this can be attributed to the
\end{abstract}

Thematic Special Issue on: Enhancing the Impact of Cross Sector Partnerships.

Domenico Dentoni

domenico.dentoni@wur.nl

Verena Bitzer

verena.bitzer@wur.nl

Stefano Pascucci

stefano.pascucci@wur.nl

1 Management Studies Group, Wageningen University, Hollandseweg 1, 6706 KN Wageningen, The Netherlands development of corporate strategies on sustainability after a few years of CSP participation, which entails a shift from a reactive to a proactive attitude towards sustainability issues and which may decrease the need or motivation for stakeholder orientation. These findings open up important issues for discussion and for future research on the impact of CSPs in a context of wicked problems.

Keywords Cross-sector partnerships $\cdot$ Stakeholder orientation - Dynamic capabilities · Wicked problems . Corporate sustainability strategies

\section{Introduction and Research Objectives}

One of the key impacts of cross-sector partnerships (CSPs) is the co-creation of resources by participating organizations through processes of engagement, knowledge exchange, and inter-organizational learning (Austin and Seitanidi 2012). Starting with diverse resources and capabilities, business and non-business organizations in CSPs can generate collaborative advantage and shared value (Teegen et al. 2004; Glasbergen 2010; Porter and Kramer 2011) by gaining and sharing information, knowledge, and skills (Austin 2000; Waddell 2000; Selsky and Parker 2005). This 'win-win' potential indicates that collaboration is likely to emerge when each partner can receive access to resources and capabilities that they would otherwise not have (Austin 2000; Waddell 2000; Rondinelli and London 2003).

Yet, to evolve and survive in a world increasingly characterized by wicked problems (Dentoni et al. 2012a; Waddock 2012), organizations participating in CSPs require more than just resources and capabilities. Wicked problems, such 
as poverty, climate change, environmental degradation or food insecurity, have no closed-form definition, emerge from complex systems in which cause and effect relationships are either unknown or highly uncertain, and have multiple stakeholders with strongly held and conflicting values related to the problem (Rittel and Webber 1973; Weber and Khademian 2008). Wicked problems require organizations to learn how to anticipate, react, harmonize, or somehow address the requests and concerns of a wide range of stakeholders (Gray 1989; Glasbergen 2007; Kolk et al. 2008; Waddock 2012). In this context, organizations need to be more oriented towards stakeholders, thus to develop a specific type of dynamic capabilities (Teece et al. 1997) that allow them to respond effectively to the concerns of multiple societal groups and thus address wicked problems. Given this organizational challenge, this study explores the impact of CSPs on the dynamic capabilities of its business participants that are needed for dealing with wicked problems. To this purpose, we introduce the concept of dynamic capabilities for stakeholder orientation to describe those dynamic capabilities which allow organizations to adapt to changing environments by effectively (1) sensing, (2) interacting with, (3) learning from, and (4) changing based on stakeholders. The impact of CSPs on the co-creation of dynamic capabilities for stakeholder orientation is relevant not only for the participating organizations, but for society as a whole, as CSPs increasingly play a governance role in society (Teegen et al. 2004). CSPs that stimulate dynamic capabilities for stakeholder orientation become effective sense-making devices (Selsky and Parker 2010) to understand the changing nature of wicked problems and to gain awareness on the consequences of partners' actions on society.

To interpret the impact of CSPs on the co-creation of dynamic capabilities for stakeholder orientation, this study follows a grounded theory approach of inductive research (Glaser and Strauss 1967; Suddaby 2006). We chose this method given the lack of a substantive theory on the cocreation of dynamic capabilities for stakeholder orientation through CSPs. This gap corresponds to a general lack of analyses seeking to assess the impact of CSPs (LundThomsen 2009; Seitanidi 2010; Van Tulder 2012), despite their rapid proliferation in practice. We provide empirical evidence on the in-depth studies of four global agri-food companies (Unilever, Friesland Campina, Sara Lee and Heinz) that developed a "portfolio of CSPs" (Van Tulder 2012) over the last 10 years. We selected the agri-food sector as empirical field of research because the tensions between land, natural resources, feed, food, and energy are recognized to be urgent wicked problems (Batie 2008). Moreover, CSPs in this sector have increased swiftly in the last decade (Dentoni and Peterson 2011).

The rest of this paper is organized as follows. "Methods: A Grounded Theory Approach" section introduces and justifies the grounded theory approach taken. "Theoretical Background" section considers partnerships from a resource/capability-based view and from a stakeholder theory perspective. Based on these two views, we develop the concept of dynamic capabilities for stakeholder orientation as a potential impact of CSPs. "Key Background Information" section gives an overview of the companies studied and their engagement in CSPs. We present and synthesize our results in testable propositions in "The Impact of Cross-Sector Partnerships on Dynamic Capabilities for Stakeholder Orientation" section. "Discussion" section explores the managerial and policy implications of the findings, while "Conclusion" section concludes.

\section{Methods: A Grounded Theory Approach}

Consistent with the pursued grounded theory approach (Glaser and Strauss 1967; Suddaby 2006), this study took place in four different stages between 2009 and 2012. The first stages were broad and unfocused to identify the points of originality and relevance of the observed phenomenon, while the following stages made the data collection and analysis more focused and systematic (Strauss and Corbin 1994).

First, in 2009 and early 2010, we joined discussion sessions during five international agribusiness conferences and conducted 34 interviews with business managers, non-governmental organizations (NGOs), and academics who participated in CSPs in the agri-food sector, specifically the Sustainable Agriculture Initiative (SAI) Platform, TransForum, The Roundtable on Responsible Soy, The Carbon Disclosure Project, and the Dutch Sustainable Trade Initiative (IDH). At this stage, we realized that the actors involved were motivated to establish CSPs not only to share resources, co-create operational capabilities, and solve specific wicked problems as they explicitly claimed, but also to develop a capacity to understand and learn systematically from their stakeholders, considering that many of them were out of their network beforehand.

Second, between 2010 and early 2011, we undertook a systematic screening of the CSPs created or joined by the 50 largest agri-food multi-national companies (MNCs; Dentoni and Peterson 2011). We chose these MNCs because of the large amount of data available through web electronic sources compared to smaller firms, and the rapid proliferation of CSPs in the agri-food sector compared to other sectors. We collected data from reports published by the MNCs, their respective CSPs, and their private and public partners. Data collected involved the number, type, and role of stakeholders participating in each partnership, the year of creation, the goal and focus area of intervention, and the governance structure of CSPs. Through this stage, 
we obtained an overview of the universe of CSPs in the global agri-food sector: 22 out of the 50 largest MNCs were involved in 38 partnerships (Dentoni and Peterson 2011). We were also able to create a broad picture of the different levels of experience that these 22 MNCs had in participating in CSPs. Importantly, we recognized that some MNCs had longer experience in participating in CSPs than others. This allowed making a purposive sample selection (Yin 2009) in the following step of the study.

Third, we selected the following four MNCs, which exhibited heterogeneous levels of experience in CSPs, for further study: Unilever has the longest experience, Friesland Campina and Sara Lee have a medium level of experience, while Heinz has the shortest experience. "Experience in CSPs" was measured qualitatively as a combination of the number of years from the first CSP participation, the number of CSPs joined, and the degree of CSP participation ("leading" founder (or co-founder) or "follower"; see "Key Background Information" section). Between 2011 and early 2012, we conducted 25 interviews with managers of the four MNCs (from sustainability/CSR, research and development, procurement and/or marketing departments) and with the representatives of their partnering organizations within CSPs (especially NGO managers; see "Appendix 1" section for detailed information). The interviews were semi-structured and focused on understanding the extent to which the MNCs are able to sense, interact with, learn from, and change based on stakeholders, and how the process of developing such capabilities took place. We used indirect questioning techniques to learn from the interviewees while attempting to minimize social desirability bias (Fisher 1993). In particular, we asked the interviewees to describe the sustainability initiatives undertaken by the four MNCs with stakeholders over time, both within and outside of CSPs. After the interviews, we triangulated our interpretations based on the written interview records.

Fourth, from late 2011 to early 2012, we undertook a systematic screening of the sustainability/CSR reports produced by the four MNCs to triangulate the primary data collected through interviews in the previous research stages. In particular, we collected secondary data from sustainability/CSR reports produced in the first year in which companies joined or created a CSP (between 2002 for Unilever and 2007 for Friesland Campina) and in the last year of reporting available (2010). We then developed exploratory measures, or proxies, for the emerging dynamic capabilities for stakeholder orientation to capture the change in sensing, interacting, learning, and changing based on stakeholders through word counting and semantics (Duriau et al. 2007). We developed a specific set of measures for each type of capability ("Appendix 2" section). For example, the measures used for sensing stakeholders relate to (i) breadth of the stakeholder portfolio (S1), (ii) relevance of stakeholders (S2), (iii) relevance of stakeholders related to the impact of a corporate sustainability initiative or strategy (S3), and (iv) the assessment of sensing capabilities by stakeholders operating outside the specific supply chain (S4). Similarly, we captured the remaining three capabilities by developing three-five measures each.

\section{Theoretical Background}

\section{Partnerships and the Co-creation of Resources and Capabilities}

From a resource-based view, a key driving force for organizations entering into CSPs is the prospect of accessing and co-creating new resources and capabilities (Austin 2000; Waddell 2000; Rondinelli and London 2003; Selsky and Parker 2005). Resources are strengths, advantages, or assets, including technical know-how, management skills, human capital, and reputation, which organizations can use to conceive of and implement their strategies (Barney 1991; Penrose 1959; Wernerfelt 1984). Among these resources, capabilities describe the ability of adapting, integrating, and reconfiguring internal and external organizational skills, resources, and functional competences (Teece et al. 1997). Accordingly, organizations are motivated to collaborate in order to develop and gain access to new external resources, particularly those that are scarce and inimitable, such as tacit knowledgerelated and competence-related resources (Dierickx and Cool 1989; Barney 1991; Peteraf 1993; Gulati 1999; Prahalad and Ramaswamy 2004). However, contrary to traditional business alliances that are characterized by low organizational diversity and high task specificity, CSPs include actors that have fundamentally different core logics, operating principles, and goals (Waddell 2002). This diversity makes collaboration more vulnerable to tensions and conflict unless trust is created (Le Ber and Branzei 2010a; Glasbergen 2011). At the same time, it creates high incentives for collaboration due to the heterogeneous resources and capabilities of partners, which can, if they are shared, produce collaborative advantage and create impact which no organization could have created on its own (Huxham 1993). Studies have distinguished between a variety of resources and capabilities among CSP participants, among which the provision of financial capital, market knowledge, and management expertise by business participants, and the provision of issue knowledge, legitimacy, and community relationships by NGOs are most frequently mentioned in the literature (Waddell 2002; Dahan et al. 2010). By participating in CSPs, businesses 
can enhance reputation, access local knowledge, and increase their corporate social responsibility performance, while NGOs can receive access to technical, organizational, and financial resources (Arts 2002; Teegen et al. 2004).

Relative to this co-creation of "operational capabilities" (Winter 2003), dynamic capabilities represent a form of "double-loop learning" or "learning how to learn" (Argyris 1977). They refer to "the ability to integrate, build and reconfigure internal and external competencies to address rapidly changing environments" (Teece et al. 1997, p. 516). Dynamic capabilities are considered critical for sustainable competitive advantage in the face of rapid technological change and the uncertain nature of future competition and markets (Teece et al. 1997; Helfat et al. 2007). Yet, addressing wicked problems, including various sustainability challenges, and responding to stakeholders' concerns changes the nature of dynamic capabilities needed by companies (Verona and Zollo 2011; Dentoni et al. 2012a) for two major reasons. First, the notion of sustainability requires the integration of economic, social, and environmental outcomes, whereas the outcomes of dynamic capabilities are traditionally defined in terms of economic efficiency/effectiveness. Second, traditional dynamic capabilities may not attend to key issues required to address sustainability challenges, including the nature of the core business activity, firm values, and strategic intent (Teece 2007). This suggests that the ability of CSPs to create impact in the form of co-creating dynamic capabilities depends on how organizations engage with their stakeholders.

\section{Partnerships and Stakeholder Theory}

The strategic value of collaboration is also recognized in stakeholder theory, which views organizations to be at the center of a network of stakeholders who can affect or are affected by the achievement of the organization's objectives (Freeman 2010). Stakeholders are defined according to their relation with the focal organization, which is usually a company (Clarkson 1995). The challenge for companies is then to accommodate the claims of stakeholders, recognizing that the long-term sustainability of their business depends on co-operative relations with these stakeholders (Freeman 2010; Donaldson and Preston 1995). Starting from the 1990s, the literature has debated on how firms should identify stakeholders as well as manage and respond to their claims (Laplume et al. 2008). According to Mitchell et al. (1997), the question of whether or not stakeholders deserve attention depends on their legitimacy, the urgency of their claims, and their (potentially threatening) power. From this perspective, developing partnerships is a vehicle for businesses to be "more socially responsible to address stakeholder demands and develop or sustain a competitive advantage" (Selsky and Parker 2005, p. 852). Yet, scholars recognize that firms may identify different stakeholders depending on their culture (Jones et al. 2007), their own life cycle (Fineman and Clarke 1996), and the industry context (Jawahar and McLaughlin 2001). Moreover, they may engage in different ways with stakeholders depending on their motivation and capacity (Lawrence 2002) and their leadership (Maak 2007).

Despite this advancement of stakeholder theory, only in the last decade have scholars started focusing on the organizational capabilities that make stakeholder orientation, identification, and engagement more effective (Ferrell et al. 2010; Verona and Zollo 2011). Cross-sector collaboration presupposes that organizations are "dedicated to learning about and addressing stakeholder issues" (Ferrell et al. 2010, p. 95) and oriented towards two-way communication and consensual decision-making (Ansell and Gash 2008). Such stakeholder orientation is an organizational culture and behavior inducing organizations to be continuously aware of and proactively act on issues that are of concern to one or more stakeholders (Maignan and Ferrell 2004; Ferrell et al. 2010). In the context of wicked problems, stakeholder orientation is critical, as organizations are forced to transcend their traditional relationship boundaries and interact with multiple stakeholders that may have differing goals and cultures (Batie 2008). This entails moving from viewing stakeholders as opponents to valuing them as complements (Freeman 2010), which, in turn, makes it easier to be structurally oriented towards each other's needs, to learn from each other and to change based on jointly agreed goals (Selsky and Parker 2010). Thus, by interacting with multiple stakeholders and tackling wicked problems, organizations mitigate and share risks, which, in the long run, increases their chances of survival (Clarkson 1995; Freeman 2010). Particularly with regard to managing wicked problems, companies increasingly realize that they need to understand, interact and, at least to some extent, adapt to the pressures of stakeholders (Ferrell et al. 2010; Hult 2011). Thus, stakeholder orientation is becoming an essential dynamic capability (Clarke and Roome 1999; Hult 2011) rather than an optional managerial attitude (Berman et al. 1999).

\section{Towards the Co-creation of Dynamic Capabilities for Stakeholder Orientation}

The argument that CSPs impact on the co-creation of resources and capabilities as well as on the relationships between organizations and their stakeholders implies that the partners themselves tend to be beneficiaries of partnerships. Such a concentration of impact for the participating organizations in CSP is not surprising, considering the amount of time and resources invested in partnerships 
(Biermann et al. 2007). To systematize the analysis of the impact of CSPs on the organizational level, this study introduces the concept of dynamic capabilities for stakeholder orientation, which help organizations manage wicked problems by responding effectively to multiple stakeholders' concerns (Verona and Zollo 2011).

The basic premise is that over time CSPs can influence the ability of organizations to react, anticipate, and harmonize the pressures of multiple stakeholders (Vurro et al. 2010; Waddock 2012) through organizational learning and relationship building (Seitanidi and Ryan 2007). From a business perspective, the ability of a firm to successfully partner with an NGO or with other cross-sector stakeholders may itself constitute a dynamic capability that can lead to competitive advantage (Dahan et al. 2010). Such capabilities do not reside in individual participants or organizations themselves, but rather depend on an array of linkages that they have with other actors in the system, and especially on their approach to participation (Robinson and Berkes 2011). This suggests that such dynamic capabilities are the result of interconnected organizations and actors, whose linkages facilitate social learning and co-creation of knowledge (Armitage et al. 2011). In this way, dynamic capabilities for stakeholder orientation can be classified as higher order dynamic capabilities that are difficult to imitate and have the potential to lead to competitive advantage.

Based on the insights from the theoretical perspectives introduced above and the empirical evidence from the interviews, this study identifies four dynamic capabilities for stakeholder orientation: sensing stakeholders, interacting with stakeholders, learning from stakeholders, and changing based on stakeholders (hereby synthesized as SILC, see Table 1).

Sensing stakeholders within CSPs is important due to the differences in mission and core logics as well as the historical aversion between partners (Austin 2000; Arts 2002). These can create conflict and distrust between partners that may constrict the formation and implementation of a partnership (Rondinelli and London 2003). Outside of CSPs, sensing stakeholders may be particularly challenging and represents a distinctive asset in a context of wicked problems, since the societal groups affected by the issues tackled within CSPs may swiftly change, making them difficult to identify (Waddock 2012).

Similar to "alliance capability" (Huxham 1993), interacting with stakeholders represents the capacity and readiness of an organization to engage with stakeholders based on reciprocal exchange. Austin (2000) suggests that partnerships require a high level of interaction in order to create value for their participants as well as society at large. Accordingly, success or failure of partnerships to a great extent depends on how partners frame their interactions, appreciate differing perspectives (Le Ber and
Branzei 2010b), and learn how to interact in a constructive manner (Roloff 2008). Especially in a context of wicked problems, the vastly different cultures, values, and goals among stakeholders within and outside CSPs create major interaction challenges which demand heightened capabilities in negotiation, communication, and reciprocal understanding.

The process of interaction is crucial for mutual learning and co-production of knowledge (Robinson and Berkes 2011). Learning from stakeholders may result from understanding and finding different approaches to the same challenges, demanding an iterative process of exchanging and combining the knowledge, experience, and competencies of the actors involved (Murphy et al. 2012). However, learning does not only concern the wicked problem which the overall partnership seeks to address, it also feeds back into the participating organizations who learn "about themselves as organizational and sectoral entities" (Selsky and Parker 2010, p. 32).

Engaging with partners through problem sharing purposefully aims at co-designing and implementing innovative solutions to address wicked problems (Murphy et al. 2012). This includes internal changes, such as altering organizational structures, and externally oriented changes, such as co-developing product and process innovations. Changing based on stakeholders is strongly correlated with improved relationships, i.e., sensing and interacting with stakeholders, and the social learning processes emanating from these (Mandarano and Paulsen 2011). Seitanidi et al. (2010) suggest that the previous history of interactions with stakeholders provides an indication of the transformative potential of organizations. In other words, organizations that lack collaboration experience may be unable to articulate their interests and competencies vis-à-vis the strategic approach of other actors, which may make it difficult to develop the transformational capacity required to promote change in the partner organizations.

\section{Key Background Information}

\section{Cross-Sector Partnerships in the Agri-food Sector}

Since 2001, 22 of the world's 50 largest MNCs in the agrifood sector have formed and/or joined CSPs with one or multiple heterogeneous stakeholders, including NGOs, governments, and knowledge institutes (Dentoni and Peterson 2011). Within this growing trend of CSP formation, MNCs have taken different approaches of engaging with stakeholders (Dentoni and Peterson 2011). The largest MNCs, such as Nestlé, PepsiCo, Kraft, and Unileverwhich each own a portfolio of brands diversified into a number of food sub-sectors-participate in a variety of 
Table 1 The four SILC dynamic capabilities for stakeholder orientation

\begin{tabular}{ll}
\hline $\begin{array}{l}\text { Dynamic capabilities for } \\
\text { stakeholder orientation }\end{array}$ & Description \\
\hline Sensing stakeholders & $\begin{array}{c}\text { The ability of identifying both existing and potential stakeholders and understanding their needs and } \\
\text { demands; recognizing conflicting views among multiple stakeholders, their dynamics and the changing } \\
\text { nature of their requests; assessing stakeholders' (tangible and intangible) resources and capabilities; } \\
\text { finding and processing information about their stakeholders to evaluate new opportunities for } \\
\text { collaboration }\end{array}$ \\
$\begin{array}{c}\text { The ability of initiating, developing, establishing, and strengthening ties with stakeholders; and assessing, } \\
\text { developing, and adapting effective formal or informal mechanisms to achieve short-term and long-term } \\
\text { goals together with both current and new stakeholders }\end{array}$ \\
$\begin{array}{c}\text { The ability of acquiring, assimilating, and transforming knowledge from stakeholders; establishing } \\
\text { adaptive procedures and routines that incorporate and codify knowledge from stakeholders into } \\
\text { organizational practices and processes }\end{array}$ \\
$\begin{array}{c}\text { The ability of using knowledge from stakeholders in organizational operations and strategies; } \\
\text { reformulating organizational structure and shifting organizational culture based on stakeholder } \\
\text { interaction; co-creating different types of innovation, such as product and process innovations, with } \\
\text { stakeholders; re-deploying organizational resources and capabilities based on changing stakeholders' } \\
\text { advice and pressure }\end{array}$
\end{tabular}

partnerships covering multiple food sectors with a broader focus on both environmental and social sustainability issues (Dentoni and Peterson 2011). Less diversified and relatively smaller MNCs, such as Bunge, Ferrero, and Friesland Campina, focus mainly on CSPs within a particular sector (e.g., cocoa, palm oil, cashew, or coffee) which correspond more closely to their core strategy. Next to their participation in CSPs, over time several MNCs have codified a strategic intent for their sustainability activities (such as Nestlé's "Shared Value Creation" model) that strictly relates to their core business strategy, and have started reporting through recently developed environmental and/or social standards (UN Global Compact, the Global Reporting Initiative, and the Carbon Footprint Disclosure).

\section{Four Companies: Cross-Sector Partnerships and Strategic Intent}

\section{Unilever: Long Experience in Cross-Sector Partnerships}

With Anglo-Dutch origins, Unilever is the world's second largest MNC manufacturing food, with a portfolio that includes more than 400 food and non-food products and brands sold in more than 180 countries. Unilever is continually broadening its portfolio by expanding existing categories into new geographies or via "bolt on" acquisitions that help to build presence, either in more countries or at a wider range of price points.

Of the four MNCs studied, Unilever has the longest history of CSP participation, starting in 1996 with the Marine Stewardship Council. Since then the company has co-founded 9 CSPs and joined another 11 CSPs (Table 2).
All these partnerships relate to strategic resources used in Unilever's core business, such as water, fish, cocoa, sugar, tea, soy, and palm oil. In 2010, Unilever launched the "Sustainable Living Plan" as a commitment to "a ten year journey towards sustainable growth." The Plan comprises three main pillars: (1) "improving health and well-being," which was designed with internal and external behavioral change experts and relies on benchmarks against a range of national dietary recommendations, (2) "reducing environmental impact," where the most significant environmental impacts of products are measured in terms of their relevance to Unilever, its stakeholders, and society, and (3) "enhancing livelihoods," including cooperation with suppliers to follow the guidelines from Unilever's Sustainable Agriculture Code. Suppliers are measured through certification and self-verification.

\section{Friesland Campina: Medium Experience in Cross-Sector Partnerships}

Friesland Campina is a multi-national dairy company with Dutch origins which is wholly owned by a dairy co-operative comprising 14,800 member dairy farms in the Netherlands, Germany, and Belgium. Its products are sold in more than 100 countries across Europe, Asia, and Africa.

Since 2003, Friesland Campina has been involved in seven CSPs. The company co-founded two CSPs related to its core business (dairy) and joined five CSPs in sectors related to its key ingredients (e.g., soy and palm oil; Table 2). Between 2008 and 2010, Friesland Campina designed a new overall strategy called "Route 2020," which integrates its core strategy with activities related to sustainability. Through Route 2020, the company aims to (1) 
Table 2 The engagement of the four companies in cross-sector partnerships

\begin{tabular}{|c|c|c|c|c|}
\hline & Unilever & Friesland Campina & Sara Lee & Heinz \\
\hline 1996 & Marine Stewardship Council (MSC) ${ }^{\mathrm{a}}$ & & & \\
\hline 2001 & $\begin{array}{l}\text { Global public-private partnership for } \\
\text { handwashing with soap }{ }^{\mathrm{a}}\end{array}$ & & & \\
\hline 2002 & $\begin{array}{l}\text { Sustainable Agriculture Initiative (SAI) } \\
\text { Platform }^{\mathrm{a}}, \text { GAIN }^{\mathrm{a}} \text {, Novella Africa } \\
\text { Initiative }^{\mathrm{a}}\end{array}$ & & & \\
\hline 2003 & & SAI Platform & & \\
\hline 2004 & $\begin{array}{l}\text { Roundtable for Sustainable Palm Oil } \\
\text { (RSPO) }^{\mathrm{a}} \text {, Sustainable Packaging } \\
\text { Coalition, Sustainable Food Lab }\end{array}$ & & $\begin{array}{l}\text { SAI Platform, UTZ Good Insight } \\
\text { Coffee Program }{ }^{\text {a }} \text {, Common Code for } \\
\text { the Coffee Community }\end{array}$ & \\
\hline 2005 & $\begin{array}{l}\text { Bonsucro; Carbon Disclosure Project } \\
\text { (CDP), Supply Chain Leadership } \\
\text { Collaboration }^{\mathrm{a}}\end{array}$ & & Ethical Tea Partnership & $\begin{array}{l}\text { Sustainable Food } \\
\text { Lab }\end{array}$ \\
\hline 2006 & Roundtable for Responsible Soy (RTRS) ${ }^{\mathrm{a}}$ & $\begin{array}{l}\text { RTRS, Global Dairy } \\
\text { Platform }^{\mathrm{a}}\end{array}$ & & \\
\hline 2007 & $\begin{array}{l}\text { CEO Water Mandate, Sustainable Tea } \\
\text { Project }^{\mathrm{a}} \text {, Greenhouse Gas Protocol } \\
\text { Initiative }\end{array}$ & RSPO & $\begin{array}{l}\text { IDH Coffee }{ }^{\mathrm{a}} \text {, UTZ Good Insight Tea } \\
\text { Program }\end{array}$ & $\begin{array}{l}\text { UTZ Good } \\
\text { Insight Cocoa } \\
\text { Program } \\
\text { RSPO }\end{array}$ \\
\hline 2008 & Water Footprint Network, IDH Soy & $\begin{array}{l}\text { Sustainable Dairy Chain } \\
\text { Initiative }^{\text {a }} \text { IDH Soy, IDH } \\
\text { Cocoa }\end{array}$ & Sustainable Forestry Initiative & IDH Cocoa ${ }^{a}$ \\
\hline 2009 & $\begin{array}{l}\text { AIM }^{\mathrm{a}} \text {, Project Laser Beam }{ }^{\mathrm{a}} \text {, IDH Tea, } \\
\text { Climate Savers Computing Initiative }\end{array}$ & & $\begin{array}{l}\text { Global Food Safety Initiative, } \\
\text { Sustainable Packaging Coalition }\end{array}$ & \\
\hline 2010 & Global Packaging Project & $\begin{array}{l}\text { UTZ Good Insight Cocoa } \\
\text { Program, Dairy } \\
\text { Development Program } \\
\text { Vietnam }\end{array}$ & Global Packaging Project & SmartWay \\
\hline 2011 & $\begin{array}{l}\text { New Vision for Agriculture }{ }^{\mathrm{a}} \text {, IDH Spices, } \\
\text { Unox and Dutch Animal Welfare } \\
\text { Organization }\end{array}$ & & & \\
\hline
\end{tabular}

a (Co)founder

grow by offering a wider range of dairy products, increasing its geographical presence, and shifting to more specialized ingredients in liaison with clients, (2) valorize milk by enhancing its natural qualities, and (3) achieve climate neutral effects of their foreseen growth by improving the energy efficiency of their member dairy farmers and chain partners, reducing greenhouse gas emissions and stimulating the production of sustainable energy on dairy farms.

\section{Sara Lee: Medium Experience in Cross-Sector Partnerships}

Sara Lee Corporation is a global consumer-goods company based in Illinois, USA. It has operations in more than 40 countries and sells its products in over 180 nations worldwide. Its largest customer is Wal-Mart Stores (WMT), responsible for $15 \%$ of its total sales.

Sara Lee has been involved in CSPs since 2004, particularly in partnerships dealing with specific commodities, such as coffee and tea (Table 2). In 2006, it created an internal sustainable working team with the goal of ensuring that sustainability activities are aligned with its global business strategy. The team is a network of members from all business units and corporate functions under the leadership of the Vice President. The implementation of sustainability into business strategies is customized for each business segment and market. In 2009, business-specific environmental goals were set at a facility level for conservation of energy and water and reduction of waste with the baseline of 2005. The target year for achieving the goals is 2012 .

\section{Heinz: Shorter Experience in Cross-Sector Partnerships}

Headquartered in Pittsburgh (Pennsylvania, USA), Heinz is a global food processing company which markets its products in more than 200 countries and territories worldwide.

Heinz joined two CSPs in 2005 and 2007 and later cocreated two CSPs in the cocoa sector, which represents one of its core businesses together with tomato (Table 2). Related to, but not included in its core strategy, Heinz codified a 
Table 3 Sensing stakeholders: empirical evidence

\begin{tabular}{|c|c|c|}
\hline Sensing & "Early" experience with CSPs & "Later" experience with CSPs \\
\hline Unilever & $\begin{array}{l}\text { 1996-2006 after its first CSP, Unilever developed a Sustainable } \\
\text { Agriculture Code through a joint process with suppliers and } \\
\text { global and local NGOs. Unilever also founded } 10 \text { CSPs } \\
\text { following a predominantly "reactive" approach to stakeholder } \\
\text { pressures. In the development of these new CSPs, Unilever } \\
\text { even attempted to partner with NGOs that strategically played } \\
\text { the outsider role in CSPs }\end{array}$ & $\begin{array}{l}\text { 2007-2012 as Unilever started developing its Sustainable Living } \\
\text { Plan, the company selected a set of stakeholders as key } \\
\text { partners in activities which fit the company's sustainability } \\
\text { agenda rather than having a set of "reactive" initiatives. The } \\
\text { company continued to increase its participation in CSPs, but } \\
\text { issues and strategies were proactively proposed to stakeholders } \\
\text { with constant reference to the Sustainable Living Plan. Outside } \\
\text { stakeholders were still welcome to join CSPs, but Unilever } \\
\text { mainly drove the CSP agenda with more experienced CSP } \\
\text { members }\end{array}$ \\
\hline $\begin{array}{l}\text { Friesland } \\
\text { Campina }\end{array}$ & $\begin{array}{l}\text { 2003-2008 after developing its first CSP, Friesland Campina } \\
\text { started engaging with NGOs that typically played an outsider } \\
\text { role in CSPs. These first experiences sensitized the company to } \\
\text { the demands and goals of NGOs, and created a better } \\
\text { understanding of whether collaboration with NGOs might be } \\
\text { feasible or could provoke resistance }\end{array}$ & $\begin{array}{l}\text { 2009-2012 after the recent establishment of "Route 2020," } \\
\text { Friesland Campina kept a focus on selected stakeholders } \\
\text { within CSPs that are strictly related to their core business. } \\
\text { NGOs were sought out for their specialized knowledge and } \\
\text { expertise on soy production. The company did not mention } \\
\text { other NGOs outside the CSPs. Managers considered many } \\
\text { NGO claims unrealistic and were only interested in engaging } \\
\text { with NGOs which could work with a long-term plan }\end{array}$ \\
\hline Sara Lee & $\begin{array}{l}\text { 2004-2008 in 2004, Sara Lee started building CSPs in the coffee } \\
\text { sector and since } 2007 \text { increasingly mentions stakeholders } \\
\text { outside their CSPs in corporate reports and interviews (in } \\
\text { particular, NGOs and research institutions). Much of the } \\
\text { communication between Sara Lee and stakeholders is } \\
\text { mediated by UTZ, a certification NGO, which has become } \\
\text { Sara Lee's key partner in most of their CSPs }\end{array}$ & $\begin{array}{l}2009-2012 \text { since Sara Lee has focused almost exclusively on } \\
\text { UTZ in its stakeholder engagement, the company has } \\
\text { expressed difficulties with interpreting the needs and pressures } \\
\text { of other stakeholders, particularly other NGOs. Sustainability } \\
\text { initiatives are closely tied to UTZ's activities in promoting } \\
\text { standards for commodity production }\end{array}$ \\
\hline Heinz & $\begin{array}{l}\text { 2005-2009 after its first CSP experience, Heinz started } \\
\text { addressing an increasing number of stakeholders outside the } \\
\text { CSPs to communicate its CSR activities-mostly } \\
\text { philanthropic activities outside the core business of the } \\
\text { company }\end{array}$ & $\begin{array}{l}\text { 2010-2012 Heinz's CSR activities have taken on a more } \\
\text { targeted character, focusing on CSPs with few stakeholders, } \\
\text { mainly NGOs, in the cocoa sector. Managers emphasized that } \\
\text { this provided more direct value to the company by delivering } \\
\text { concrete outcomes, such as certification of carbon emission } \\
\text { assessments }\end{array}$ \\
\hline
\end{tabular}

"Sustainability Process" to provide a customizable sustainability program for each business unit under a business model embodying Heinz's strategy. Set up unilaterally in 2005 with the target year of 2015, these sustainability goals are related to reducing energy consumption, greenhouse gas emissions, solid waste, water consumption, and total packaging material; increasing renewable energy and employee engagement through an awareness and voluntary personal sustainability campaign; improving tomato agriculture by reducing water and carbon footprint; and increasing tomato crop yields through the use of hybrid tomato seeds.

\section{The Impact of Cross-Sector Partnerships on Dynamic Capabilities for Stakeholder Orientation}

\section{CSP Experience and Sensing Stakeholders}

Empirical evidence indicates that, although starting from different initial levels, in the years after founding the first
CSPs companies' capability of sensing stakeholders both within and outside the partnerships increased. Yet, with growing experience in CSP participation, the capability of the four MNCs to sense stakeholders outside existing CSPs decreased (Table 3). Since experience in CSP is measured as a combination of qualitative variables, the "early" rather than "later" level of experience (as in Table 3 and following) is approximate and subject to interpretation. Unilever's "early" stage is considered to be 10 years (1996-2006) as the company took a long time to participate in other CSPs after founding the first one. On the other hand, Heinz's "later" stage is restricted to only 2 years (2010-2012) because the company has the shortest experience with CSPs. This pattern of increasing and then decreasing sensing capabilities across the four companies leads to the following proposition:

P1 Increased experience in CSPs has an inverted U-shaped effect on companies' capability of sensing stakeholders over time. That is, as companies become more experienced in CSP participation, their capability of sensing stakeholders first increases and then decreases. 
Table 4 Interacting with stakeholders: empirical evidence

\begin{tabular}{|c|c|c|}
\hline Interacting & "Early" experience with CSPs & "Later" experience with CSPs \\
\hline Unilever & $\begin{array}{l}\text { 1996-2006 Unilever demonstrated the ability of opening and } \\
\text { leading stakeholder dialogs by founding CSPs and taking an } \\
\text { active role, and by establishing communication with } \\
\text { stakeholders outside of CSPs, including activist and advocacy } \\
\text { groups }\end{array}$ & $\begin{array}{l}\text { 2007-2012 Unilever managers codified the process of how to } \\
\text { manage stakeholder interactions based on information sharing, } \\
\text { discussing stakeholders' goals, and building trust. Consistent } \\
\text { with the Sustainable Living Plan, the company encouraged } \\
\text { managers to take the initiative in building partnerships, } \\
\text { networks, or ad hoc negotiations with stakeholders at local and } \\
\text { global level }\end{array}$ \\
\hline $\begin{array}{l}\text { Friesland } \\
\text { Campina }\end{array}$ & $\begin{array}{l}2003-2008 \text { initially, Friesland Campina was hesitant to } \\
\text { cooperate with NGOs as the company was anxious to reveal } \\
\text { confidential business information. As a result, the company } \\
\text { joined a number of CSPs, but did not take the lead in any }\end{array}$ & $\begin{array}{l}\text { 2009-2012 over time, the responsible managers became more } \\
\text { experienced in collaborating and sharing information with } \\
\text { stakeholders in CSPs. The increased capability to interact with } \\
\text { stakeholders is also reflected in the Route } 2020 \text { strategy which } \\
\text { emphasizes the importance of stakeholder dialog }\end{array}$ \\
\hline Sara Lee & $\begin{array}{l}\text { 2004-2008 Sara Lee mainly established interactions with a } \\
\text { certification NGO (UTZ) as key partner and reference point in } \\
\text { CSPs. Dialog with other stakeholders, both within and outside } \\
\text { of CSPs, remained limited. In coffee-related CSPs, Sara Lee } \\
\text { took the lead in shaping the dialog. In other CSPs, Sara Lee } \\
\text { played a follower role }\end{array}$ & $\begin{array}{l}\text { 2009-2012 Sara Lee took the initiative to expand interaction in } \\
\text { CSPs from coffee to the tea sector, although with similar } \\
\text { stakeholders and with the key mediation by UTZ }\end{array}$ \\
\hline Heinz & $\begin{array}{l}\text { 2005-2009 Heinz has established interactions with UTZ as key } \\
\text { partner and reference point in CSPs. The dialog with other } \\
\text { stakeholders within and outside CSPs remained limited }\end{array}$ & $\begin{array}{l}\text { 2010-2012 Heinz took the lead in establishing dialog and } \\
\text { steering the agenda of a CSP in the cocoa sector. In other } \\
\text { CSPs, Heinz continued to play a follower role }\end{array}$ \\
\hline
\end{tabular}

A key factor that drives such an inverted U-shaped effect seems to be the development of a corporate strategy on sustainability. Unilever started developing its Sustainable Living Plan in 2007 and launched it in 2010. Friesland Campina did so with their Route 2020 strategy, published in 2010. Sara Lee and Heinz developed specific targets on greenhouse gas emissions and certified procurement in the late 2000s. Over time, this trend of increased strategic focus made companies more proactive in sensing and understanding established partners within CSPs and less reactive to the demands of stakeholders outside of CSPs (Table 3). It could be argued that this could be interpreted as a decrease in the motivation rather than a decrease of a dynamic capability of sensing stakeholders. Yet, the adoption of a corporate strategy pre-defining scope, goals, and partners limits companies' opportunity of re-deploying organizational resources and skills to understand and react to stakeholders outside CSPs. Therefore, while developing a corporate strategy during early stages of CSP experience is a voluntary corporate action, the decreased capability of sensing stakeholders over time seems to be an involuntary side effect of developing such a strategy.

Relative to the inverted U-shaped effect of CSP experience on firms' sensing capability, two notes of caution are needed. First, the proposition indicates a pattern of change over time, but the initial and final levels of sensing capabilities vary significantly across companies. Some companies demonstrated a higher capability of sensing stakeholders than other companies. This might depend on factors such as resources available to the firms, history, culture, leadership, and the location of their headquarters. Second, after the described decrease, firms' sensing capabilities may increase again if firms realize the risks of not sensing stakeholders outside of CSPs. For instance, sensing capabilities may increase again as CSP experience further develops or as pressure on companies grows, either from stakeholders outside of CSPs or from internal stakeholders that decide (or threaten) to exit CSPs.

\section{CSP Experience and Interacting with Stakeholders}

As described in Table 4, due to growing CSP experience, the four companies continually increased their capability of interacting with stakeholders over time. This leads to the following proposition:

P2 Increased experience in CSPs has a positive effect on companies' capability of interacting with stakeholders over time. That is, as companies become more experienced in CSP participation, their capability of interacting with stakeholders continually increases.

The increased capability of interacting with stakeholders is not surprising, neither from a managerial nor an institutional standpoint. Interviews with company managers confirmed a learning curve for the organizations on how to establish interactions and collaboration with new stakeholders outside their supply chain, especially NGOs and nonbusiness organizations. After the first experience of engaging 
Table 5 Learning from Stakeholders: empirical evidence

\begin{tabular}{|c|c|c|}
\hline Learning & "Early" experience with CSPs & "Later" experience with CSPs \\
\hline Unilever & $\begin{array}{l}\text { 1996-2006 as Unilever participated in its first CSPs, the } \\
\text { company focused mostly on developing broad knowledge to } \\
\text { understand issues from a societal point of view. To integrate } \\
\text { knowledge from stakeholders, Unilever established new } \\
\text { internal processes and slowly developed a culture of learning } \\
\text { from stakeholders. At the same time, the company created a } \\
\text { mechanism to share information with a variety of stakeholders } \\
\text { through the "Growing for the Future" initiative }\end{array}$ & $\begin{array}{l}\text { 2007-2012 after having participated in a wide range of CSPs, } \\
\text { Unilever increasingly reduced its openness to stakeholder } \\
\text { knowledge and became predominantly interested in technical } \\
\text { knowledge to further the objectives of its Sustainable Living } \\
\text { Plan. New CSPs were founded with these objectives in mind, } \\
\text { i.e., to obtain detailed information on specific issues }\end{array}$ \\
\hline $\begin{array}{l}\text { Friesland } \\
\text { Campina }\end{array}$ & $\begin{array}{l}2003-2008 \text { during their first CSP on sustainable soy, managers } \\
\text { of Friesland Campina realized that they needed to adopt a } \\
\text { different mindset in order to learn from stakeholders. They } \\
\text { acknowledged that their own knowledge on sustainable soy } \\
\text { production was limited and that other stakeholders, } \\
\text { particularly NGOs, had expertise which the company needed. } \\
\text { This realization facilitated the process of integrating external } \\
\text { knowledge }\end{array}$ & $\begin{array}{l}\text { 2009-2012 as Friesland Campina developed its Route } 2020 \\
\text { strategy, learning from stakeholders became more targeted and } \\
\text { strategic. The company dealt with a few selected stakeholders } \\
\text { from within CSPs to receive access to detailed technical } \\
\text { knowledge rather than broader, agenda-setting information }\end{array}$ \\
\hline Sara Lee & $\begin{array}{l}2004-2008 \text { by joining its first CSPs, Sara Lee specifically aimed } \\
\text { to learn about sustainability assessment methods from } \\
\text { stakeholders, for instance, with regard to greenhouse gas } \\
\text { emissions, sustainable coffee production, life cycle and cleaner } \\
\text { production technologies, and supply chain traceability }\end{array}$ & $\begin{array}{l}\text { 2009-2012 the first engagement period formed the basis for Sara } \\
\text { Lee to further develop its technical knowledge in collaboration } \\
\text { with stakeholders from within CSPs. Focus areas included its } \\
\text { work with stakeholders to streamline carbon emission } \\
\text { calculations in the coffee industry and to quantify the impact } \\
\text { of transport and packaging on the environment }\end{array}$ \\
\hline Heinz & $\begin{array}{l}\text { 2005-2009 although Heinz joined a number of CSPs, the } \\
\text { company implemented only few activities to absorb and codify } \\
\text { knowledge from stakeholders. Discussions with stakeholders } \\
\text { remained at a rather broad level and were hardly integrated } \\
\text { internally, with the result that Heinz gained only limited } \\
\text { specified knowledge from stakeholders }\end{array}$ & $\begin{array}{l}\text { 2010-2012 as its experience in participating in CSPs increased, } \\
\text { Heinz moved away from the broad discussions and started } \\
\text { developing detailed technical knowledge in collaboration with } \\
\text { individual stakeholders, for instance, on assessment methods } \\
\text { for sustainable production and carbon emissions }\end{array}$ \\
\hline
\end{tabular}

with new stakeholders in CSPs, managers sought further opportunities to collaborate-either with the same partners or with new stakeholders having a similar background and culture - as they expected to become more efficient in taking joint decisions. From an institutional point of view, once they had joined one or more new CSPs with stakeholders, the companies could efficiently use the same CSP governance structure to extend the interaction with existing stakeholders, either discussing new sustainability issues or the same issues in new sectors or geographical areas, or establish ties with new stakeholders within the frame of their emerging corporate sustainability strategies.

Similar to the stakeholder sensing capabilities, also the capability of interacting with stakeholders varied across the four companies. Over time, some companies led discussions in CSPs on sustainability problems that were "very wicked," that is, global, particularly messy, urgent, and with a larger number of actors' interests to orchestrate (Levin et al. 2012). These interactions required an intense learning process, as the aspects of the problems to be discussed required more time, resources, and participation. Other companies chose not to expand their stakeholder interaction, but rather intensify the engagement with a smaller set of stakeholders, mainly for the adoption and implementation of specific social or environmental standards.

\section{CSP Experience and Learning from Stakeholders}

Empirical evidence shows that the relationship between CSP experience and the capability of learning from stakeholders follows an inverted U-shaped pattern similar to stakeholder sensing in P1 (Table 5). Initially, during the development of the first CSPs, companies rapidly "learned how to learn" from stakeholders. However, as their experience in CSPs increases over time, their capability of learning from stakeholders seemed to decrease. Data suggest that three out of the four companies (Unilever, Friesland Campina, and Sara Lee) mainly kept focusing on learning from stakeholders within the established CSPs, but not from new stakeholders outside the early founded CSPs. Heinz has a shorter experience with CSPs and still seems to be in the growing stage of learning from stakeholders (Table 5). This leads to the following proposition:

P3 Increased experience in CSPs has an inverted U-shaped effect on companies' capability of learning from stakeholders over time. That is, as companies gain more experience in participating in CSPs over time, their capability of learning from stakeholders first increases and then decreases.

Similar to sensing, also the inverted U-shaped effect of CSP experience on learning from stakeholders seems to be 
Table 6 Changing based on stakeholders: empirical evidence

\begin{tabular}{|c|c|c|}
\hline Changing & "Early" experience with CSPs & "Later" experience with CSPs \\
\hline Unilever & $\begin{array}{l}\text { 1996-2006 during its early years of CSP participation, } \\
\text { Unilever developed a "Sustainable Agriculture Code" in } \\
\text { consultation with stakeholders to introduce stricter standards } \\
\text { and controls in supply chains. The company also adopted } \\
\text { different standards developed by its various CSPs, including } \\
\text { standards for sea food and timber }\end{array}$ & $\begin{array}{l}2007-2012 \text { with the establishment of the Sustainable Living } \\
\text { Plan, Unilever sought to both centralize as well as } \\
\text { standardize its various commitments for organizational } \\
\text { change by defining a list of } 50 \text { key targets. All targets were } \\
\text { identified internally, cover a variety of issue areas, and } \\
\text { concern the company itself and its suppliers }\end{array}$ \\
\hline $\begin{array}{l}\text { Friesland } \\
\text { Campina }\end{array}$ & $\begin{array}{l}2003-2008 \text { as Friesland Campina started participating in CSPs } \\
\text { for palm oil and cocoa, it also implemented the standards } \\
\text { adopted by the respective CSPs. Company managers } \\
\text { described this as a change of company culture following CSP } \\
\text { participation }\end{array}$ & $\begin{array}{l}\text { 2009-2012 Friesland Campina continued to expand the use of } \\
\text { the previously adopted standards in palm oil and cocoa, but } \\
\text { there is no evidence for further organizational change }\end{array}$ \\
\hline Sara Lee & $\begin{array}{l}\text { 2004-2008 Sara Lee implemented substantial organizational } \\
\text { changes after joining its first CSPs. Most notably, the } \\
\text { company started using certification for coffee production and } \\
\text { sourcing, which it promoted by implementing capacity } \\
\text { building programs in the countries of production. Changes } \\
\text { also pertained to the company's use of other raw materials } \\
\text { and packaging materials, and its sustainability reporting }\end{array}$ & $\begin{array}{l}\text { 2009-2012 Sara Lee continued to expand the use of } \\
\text { certification, particularly for coffee, as commenced during its } \\
\text { earlier CSP experience. The company has not implemented } \\
\text { any new changes based on stakeholders }\end{array}$ \\
\hline Heinz & $\begin{array}{l}2005-2009 \text { Heinz implemented changes to its cocoa and } \\
\text { tomato supply chains by introducing an existing standard } \\
\text { (cocoa) and by developing new production guidelines } \\
\text { (tomato) based on its participation in CSPs }\end{array}$ & $\begin{array}{l}\text { 2010-2012 Heinz introduced further organizational changes as } \\
\text { it joined new CSPs, focusing particularly on supply chain } \\
\text { standards. Other changes concerning energy use and best } \\
\text { practices were implemented with internal resources or advice } \\
\text { from consultants }\end{array}$ \\
\hline
\end{tabular}

influenced by the development of a corporate strategy on sustainability. While all cases appear to follow the trend of first increased and then decreased learning capability, a distinction can be made between different types of learning. Companies that interacted with a large set of stakeholders on "very wicked" sustainability issues co-created broader knowledge to understand which practices are acceptable for a large number of stakeholders participating in the discussion. This can be considered a type of social learning which deals with problem framing and re-framing based on joint information sharing and knowledge development. We see that Unilever and Friesland Campina initially engaged in this type of learning. On the other hand, companies that built relationships with only few stakeholders based on a specific topic focused on technical learning to understand measurement and assessment issues, and establish indicators and criteria. Sara Lee and Heinz, but also Unilever and Friesland Campina in their later stages of CSP experience, appear to follow this strategy of technical learning.

\section{CSP Experience and Changing Based on Stakeholders}

As the experience with CSPs increases, the capability of the four companies to change based on stakeholders first seemed to increase and then to decrease (Table 6). In other words, the capability of changing based on stakeholders follows the same pattern as sensing and learning from stakeholders. During their early experience with CSPs, the companies studied featured a high ability to implement organizational changes based on their engagement with stakeholders. With growing experience, however, the companies seemed to significantly slow down and "merely" follow through with the changes agreed upon in the earlier years of their CSP participation (Table 6). This does not imply that the companies stagnated, but rather that any type of new change appeared to be based on internal initiatives instead of stakeholders. Only Heinz still seems to be in the stage of significant change given its shorter CSP experience (Table 6). This leads to the following proposition:

P4 Increased experience in CSPs has an inverted U-shaped effect on companies' capability of changing based on stakeholders over time. That is, as companies become more experienced in CSP participation, their capability of changing based on stakeholders first increases and then decreases.

Similar to sensing and learning from stakeholders, also the capability of changing based on stakeholders is influenced by the development of a corporate sustainability strategy. Based on their CSP experience and an earlier period of reaction to stakeholder pressures, the companies became proactive in addressing sustainability issues, either on a broad range of issues or in a specific domain. In other 
words, a company's corporate strategy on sustainability has become more important as a driver for organizational change than the agenda of stakeholders.

\section{Discussion}

The findings from our four cases suggest that the experience of companies in participating in CSPs has a significant effect on their dynamic capabilities for stakeholder orientation. With regard to companies' ability to sense, learn from, and change based on stakeholders, increased experience in CSPs appears to have an inversed U-shaped effect, indicating first a positive (increasing) and later on a declining effect of CSPs. We do not propose that this decline in capabilities brings back companies to the (low) capability levels prior to the partnership experiences, as companies retain and reutilize their capabilities to some extent through continuous involvement in CSPs. However, companies are not able to uphold the steep increase in capabilities which results from initial experiences in CSPs. Only the capability of companies to interact with stakeholders appears to continually increase as they become more versed in participating in CSPs. The resulting four propositions described above are visualized in Fig. 1 and synthesized as a theoretical framework in Fig. 2.

Our interpretation is that the underlying cause of such an inverted U-shaped effect with regard to sensing, learning, and changing is the development of a corporate sustainability strategy. During the early stages of CSP participation, companies are more reactive and thus more attentive to their external environment in order to identify issues and partners from a broad set of stakeholders. After identifying a number of key stakeholders as partners, companies elaborate strategies that take into account (some of) the

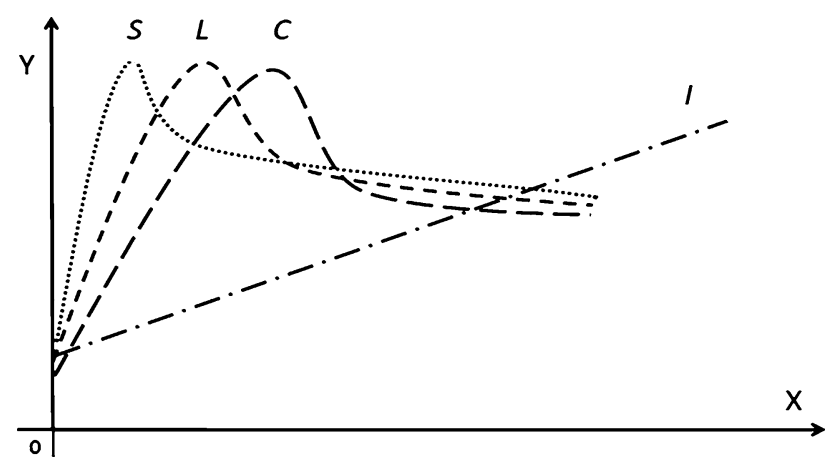

Fig. 1 Relationship between CSP experience and dynamic capabilities for stakeholder orientation. Source own elaboration based on collected data. Explanation: $X$ level of CSP experience, $Y$ dynamic capabilities for stakeholder orientation, $S$ sensing stakeholders, $I$ interacting with stakeholders, $L$ learning from stakeholders, $C$ changing based on stakeholders sustainability principles co-developed with their new partners in CSPs. As they move towards the implementation phase and design programs to reach their newly established goals, companies limit their search for new stakeholders and also their openness to learn from new stakeholders, which then affects their ability to change based on new stakeholders.

Two points of discussion arise from this interpretation of findings. First, what are the benefits and risks, both for companies and for society, if companies develop sustainability strategies that decrease their dynamic capabilities for stakeholder orientation? From a company perspective, the development of a corporate strategy on sustainability may serve as isomorphic adaptation to the expectations of external stakeholders, as strategic manipulation of these expectations, and as a means for moral reasoning (Scherer et al. 2013). This may not only increase the legitimacy of companies in complex environments (Scherer et al. 2013), at least temporarily, but can also decrease transaction costs, as companies need to invest less resources to search and coordinate with new stakeholders. Moreover, companies with a dedicated sustainability strategy may strengthen their distinctive value proposition to customers in order to create competitive advantage that may be "more sustainable than conventional and cost and quality improvements" (Porter and Kramer 2011, p. 16). At the same time, decreasing dynamic capabilities for stakeholder orientation pose longer term risks for the organization and society. Companies risk becoming unperceptive, disengaged, and unreactive to the pressures of stakeholders outside of CSPs (Hospes et al. 2012), and therefore risk their sustainability strategies to be delegitimized (Hult 2011). Ultimately, low capabilities of understanding and reacting to stakeholders that were not considered in their strategy development may compromise companies' growth and

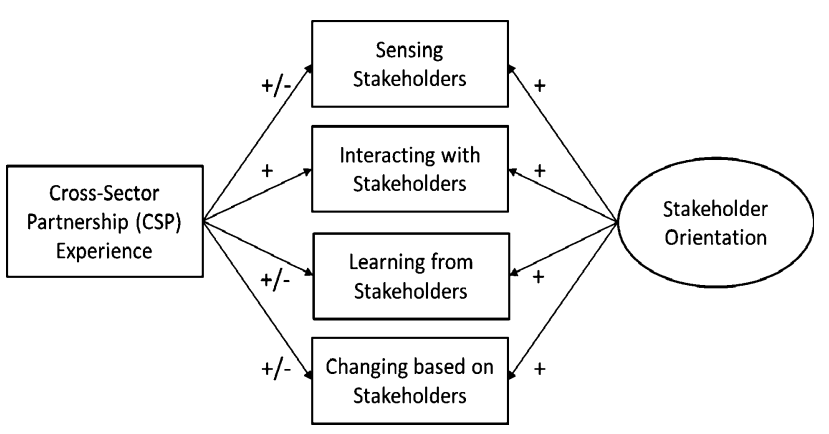

Fig. 2 Proposed theoretical framework: the impact of cross-sector partnerships on dynamic capabilities for stakeholder orientation. Explanation: + indicates a positive relationship, - indicates a negative relationship, $+/-$ indicates an inverted U-shaped relationship 
even survival (Freeman 2010). From a societal standpoint, companies that are oriented only towards a restricted set of stakeholders in CSPs do not tackle wicked problems (Dentoni et al. 2012b; Waddock 2012). This could compromise the positive impact of CSPs on under-represented company stakeholders (Bitzer 2012) and make sustainability problems even more wicked (Hospes et al. 2012; Levin et al. 2012).

Second, how can companies and their stakeholders prevent the risk of decreasing dynamic capabilities for stakeholder orientation to enhance the positive impact of CSPs? Four organizational issues stand out from a company perspective. First, research suggests that the capability to form and maintain inter-organizational alliances requires the institutionalization of codification processes to accumulate know-how across the organization (Kale and Singh 2009). Tools and templates to assist managers in identifying and assessing opportunities for collaboration play a critical role in facilitating replication and transfer of capabilities within an organization (Kale and Singh 2009). Second, feedback mechanisms at different levels allow organizations to build reflective capacity and maintain a "reflective discourse" on organizational practices vis-à-vis their external stakeholders and CSP partners (Scherer et al. 2013). Third, traditional elements of organizational stability, such as identity, need to be paired with organizational flexibility (Schreyögg and Sydow 2010), especially considering that also the partner organizations and the collaborations with them continuously change (Huxham 1993). Finally, strengthening communication and engagement between managers involved in CSPs and the "regular" internal organization helps improve the organization's orientation towards its partners, leverage relevant internal capabilities, and identify and implement new partnering opportunities.

Companies' stakeholders, including CSP facilitators, also have a role to play in preventing declining dynamic capabilities for stakeholder orientation. First, stakeholders within CSPs have the opportunity of constantly reassessing their organizational fit vis-à-vis their corporate partners, as well as of strategically shifting between supporter and opponent roles depending on companies' behavior. This holds particularly for NGOs due to their flexibility in applying both strategies of insiders and outsiders (Teegen et al. 2004). When sensing that companies do not adequately address sustainability problems and stakeholders outside of CSPs, NGOs can change their engagement strategy and move from insiders to outsiders of CSPs to provoke renewed attention by companies (Pesqueira and Verburg 2012). Second, stakeholders outside of CSPs, such as policy-makers and academics, can play a critical role in facilitating the interactions of CSPs with a wider societal audience and with other CSPs that operate in a similar space (Hospes et al. 2012). This could help increase awareness and harness the parallel development of different initiatives which may ultimately raise the benchmark for corporation's engagement in CSPs.

\section{Conclusion}

Over the last 10 years, CSPs have emerged as novel organizational forms that allow members to co-create resources and capabilities in order to move towards their established sustainability goals (Austin 2000; Rondinelli and London 2003). Yet, in a context of wicked problems faced by CSPs, structuring sustainability challenges and defining joint goals are complex, if not impossible, and require coordination with a broad, often undefined set of stakeholders (Waddock 2012). To deal with wicked problems, both participants in CSPs and society would benefit from organizations that are able to re-deploy their resources and capabilities based on a continuous process of stakeholder identification and engagement (Ferrell et al. 2010; Freeman 2010; Hult 2011). In this paper, we first introduced the concept of dynamic capabilities for stakeholder orientation to describe organizations' ability to sense their stakeholders, interact with them, learn from them, and change accordingly. Second, we explored the impact of companies' experience in CSPs on the creation of dynamic capabilities for stakeholder orientation together with (thus, "co-creation") other CSP members. Findings from four companies selected based on their heterogeneous levels of CSP experience suggest that companies developed their dynamic capabilities for stakeholder orientation in the early stages of their CSP experience and then decreased at a later stage. We interpret this inverted U-shaped effect of CSPs on the co-creation of dynamic capabilities for stakeholder orientation as the effect of companies developing corporate strategies on sustainability after a few years (between 5 and 10) of participation in CSPs. On the basis of this interpretation, we discussed the implications of the impact of CSPs on companies' dynamic capabilities for stakeholder orientation over time. On one hand, organizations and society may benefit from companies that have proactive strategies rather than reactive ad hoc initiative to address sustainability issues. On the other hand, in a context of wicked problems, organizations and society may encounter risks if companies and their crosssector partners do not continue sensing, engaging, learning, and changing based on stakeholders outside of CSPs.

The results from this study are exploratory in nature and subject to multiple interpretations. Specifically, individual factors (such as leadership styles and CEO commitment), organizational factors (such as the history, culture, and legal structure of corporations), and inter-organizational factors (for instance, goal deviation and power differences 
within CSPs, the civil society base in the countries where the firm operates, the style of stakeholder pressure, and its change over time) may also shape companies' dynamic capabilities for stakeholder orientation in interaction with or in substitution to the CSP experience. These factors are not analyzed in this study and future research would expand knowledge by considering them. Moreover, to make these findings more general, future research may test the proposed framework with other companies within or outside the agri-food sector, or even with other organizations participating in CSPs (NGOs, MNCs' chain partners, governments, knowledge institutions). A challenge for testing the proposed framework with a deductive method is to develop measures of dynamic capabilities for stakeholder orientation that go beyond asking direct questions to managers (Berman et al. 1999; Yau et al. 2007). In this direction, Cuppen (2012) developed a quasi-experimental methodology to test the outcomes of stakeholder interaction. A similar methodology could be used to test for other dynamic capabilities for stakeholder orientation.

While this study focused on the effect of CSPs on corporate capabilities, a question that remains open is how CSPs impact the dynamic capabilities for stakeholder orientation of non-business partners. Do NGOs, academics, policymakers, and other civil society organizations enhance their ability to sense, interact, learn, and change based on stakeholders as they participate in CSPs? Or do we perhaps see a similar pattern as with the four companies studied in this article? Analyzing whether the observed inverted U-shaped effect on the capabilities of sensing, learning, and changing is indeed a "corporate" phenomenon or a general impact of
CSPs would hence be an interesting avenue for further research.

Finally, the implications of our results on the impact of CSPs on dynamic capabilities for stakeholder orientation require a normative discussion. From the point of view of CSP facilitators, company managers, and stakeholders, our results beg the question if dynamic capabilities for stakeholder orientation are ultimately desirable for organizations. If so, to what extent are they desirable? One possible explanation of the inverted U-shaped effect of CSPs on stakeholder orientation is that organizations with a long CSP experience reach a higher order level of learning. This allows them to purposively select the stakeholders to sense, learn from, and implement change with based on a proactive strategic sustainability intent. A competing reflection may see this decrease in dynamic capabilities for stakeholder orientation over time as dangerous: organizations that lose the ability to assess the environment external to their purposive networks are exposed to higher risks, especially in turbulent times. Future studies are needed to expand and inform this discussion.

Open Access This article is distributed under the terms of the Creative Commons Attribution 4.0 International License (http://creativecommons.org/licenses/by/4.0/), which permits unrestricted use, distribution, and reproduction in any medium, provided you give appropriate credit to the original author(s) and the source, provide a link to the Creative Commons license, and indicate if changes were made.

\section{Appendix 1}

See Table 7.

Table 7 Interviews conducted for the four cases

\begin{tabular}{lll}
\hline Organization and function of interviewee & Type of interview & Duration (min) \\
\hline Friesland Campina, Corporate Environmental Affairs and Sustainability Manager & Face-to-face & 90 \\
Heinz, Technology Development Manager & Face-to-face & 60 \\
Heinz, Marketing Manager (International) & Face-to-face & 60 \\
Heinz, Marketing Manager (Netherlands) & Face-to-face & 45 \\
Sara Lee, Corporate Social Responsibility Manager (Netherlands) & Face-to-face & 70 \\
Sara Lee, Supply Chain Manager & Face-to-face & 30 \\
Sara Lee, Procurement Manager (Coffee) & Face-to-face & 30 \\
Sara Lee, International Corporate Social Responsibility Director & Face-to-face & 40 \\
Unilever, Global Sourcing Manager & Face-to-face \\
Unilever, Global Integration R\&D Manager & Face-to-face \\
Unilever, Sustainability Business Manager (Benelux) & Face-to-face & 70 \\
Ahold, Procurement Manager & Phone & 60 \\
Mars, Sustainability Manager & Phone & 60 \\
IDH Director International Public Affairs & Face-to-face \\
IDH Tea, Senior Program Manager & Face-to-face \\
IDH Aquaculture, Senior Program Manager & Phone & 60 \\
IDH Coffee, Interim Manager & Phone & 30 \\
\hline
\end{tabular}


Table 7 continued

\begin{tabular}{lll}
\hline Organization and function of interviewee & Type of interview & Duration (min) \\
\hline IDH Cocoa, Senior Program Manager & Phone & 60 \\
Sustainable Agricultural Initiative (SAI) Platform, General Manager & Phone & 60 \\
Managing Director, GlobalGAP & Face-to-face & 30 \\
WWF, Market Transformation Initiative Director & Face-to-face & 60 \\
SOMO, Senior Researcher & Phone & 45 \\
Oxfam Novib, Corporate Social Responsibility Policy Advisor & Face-to-face & 60 \\
Oxfam Novib, Private Sector Coordinator & Face-to-face & 90 \\
UTZ, Field Director & Face-to-face & 60 \\
\hline
\end{tabular}

The interviews took place between May 2011 and March 2012

\section{Appendix 2}

See Table 8 .

Table 8 Measures of dynamic capabilities for stakeholder orientation

\begin{tabular}{|c|c|c|}
\hline Measurement & Scale & Source(s) \\
\hline \multicolumn{3}{|l|}{ Sensing stakeholders (S) } \\
\hline $\begin{array}{l}\text { S1 Breadth of stakeholder portfolio (number of } \\
\text { different stakeholders) } \\
\text { (a) NGOs and civil society organizations } \\
\text { (b) Governments, public agencies, state departments } \\
\text { (c) Universities and research centers } \\
\text { (d) International organizations, UN agencies } \\
\text { (e) Other stakeholders (e.g., partnerships) }\end{array}$ & $\begin{array}{l}\text { Number of different stakeholders mentioned in set of } \\
\text { global corporate reports/year } \\
\text { S1.1 Absolute number } \\
\text { S1.2 Relative number/estimated total number of words } \\
\text { or pages }\end{array}$ & $\begin{array}{l}\text { Corporate report } \\
\text { CSR/sustainability report }\end{array}$ \\
\hline $\begin{array}{l}\text { S2 Relevance of stakeholders (number of total } \\
\text { stakeholders) } \\
\text { (a) NGOs and civil society organizations } \\
\text { (b) Governments, public agencies, state departments } \\
\text { (c) Universities and research centers } \\
\text { (d) International organizations, UN agencies } \\
\text { (e) Other stakeholders (e.g., partnerships) }\end{array}$ & $\begin{array}{l}\text { Number of times each stakeholder is mentioned in set of } \\
\text { global corporate reports/year } \\
\text { S2.1 Absolute number } \\
\text { S2.2 Relative number/estimated total number of words } \\
\text { or pages }\end{array}$ & $\begin{array}{l}\text { Corporate report } \\
\text { CSR/sustainability report }\end{array}$ \\
\hline $\begin{array}{l}\text { S3 Relevance of stakeholders related to the impact of a } \\
\text { corporate sustainability initiative or strategy } \\
\text { (a) NGOs and civil society organizations } \\
\text { (b) Governments, public agencies, state departments } \\
\text { (c) Universities and research centers } \\
\text { (d) International organizations, UN agencies } \\
\text { (e) Other stakeholders (e.g., partnerships) }\end{array}$ & $\begin{array}{l}\text { Number of times each stakeholder is mentioned in } \\
\text { relation to the impact of a corporate sustainability } \\
\text { initiative or strategy in set of global corporate reports/ } \\
\text { year } \\
\text { S3.1 Absolute number } \\
\text { Note this number will be a subset of the absolute number } \\
\text { of measure S2 }\end{array}$ & $\begin{array}{l}\text { Corporate report } \\
\text { CSR/sustainability report }\end{array}$ \\
\hline $\begin{array}{l}\text { S4 Assessment of sensing capabilities of stakeholders } \\
\text { outside the supply chain that are mentioned in reports }\end{array}$ & $\begin{array}{l}\text { Likert scale from } 1 \text { to } 5 \text { based on semantics of set of } \\
\text { stakeholder documents/year }\end{array}$ & $\begin{array}{l}\text { Reports, press releases, } \\
\text { official documents } \\
\text { (External validation) }\end{array}$ \\
\hline \multicolumn{3}{|l|}{ Interacting with stakeholders (I) } \\
\hline $\begin{array}{l}\text { I1 Number of negative statements of stakeholders } \\
\text { outside the chain: } \\
\text { (a) NGOs and civil society organizations mentioned } \\
\text { in corporate reports } \\
\text { (b) NGOs and civil society organizations identified as } \\
\text { most influential }\end{array}$ & $\begin{array}{l}\text { I1.1 Number of negative statements in press releases, } \\
\text { etc./year } \\
\text { I1.2 Number of negative statements in press releases, } \\
\text { etc./year (software Uni Amsterdam) }\end{array}$ & $\begin{array}{l}\text { Reports, press releases, } \\
\text { official documents } \\
\text { (External validation) }\end{array}$ \\
\hline
\end{tabular}


Table 8 continued

Measurement
I2 Assessment of interacting = dialoguing capabilities
of stakeholders outside the supply chain that are
mentioned in corporate reports
I3 Total investments in financial support of
sustainability initiatives with stakeholders
(a) NGOs and civil society organizations
(b) Governments, public agencies, state departments
(c) Universities and research centers
(d) International organizations, UN agencies
(e) Other stakeholders (e.g., partnerships)

I4 Role played in the sustainability initiatives with stakeholders

I5 Involvement in sustainability initiatives

Learning from stakeholders (L)

L1 Breadth of learning from external stakeholders on sustainability principles

(a) NGOs and civil society organizations

(b) Governments, public agencies, state departments

(c) Universities and research centers

(d) International organizations, UN agencies

(e) Other (specify)

L2 Level of detail (depth) of learning from external stakeholders on sustainability principles

(a) NGOs and civil society organizations

(b) Governments, public agencies, state departments

(c) Universities and research centers

(d) International organizations, UN agencies

(e) Other (specify)

L3 Assessment of learning capabilities of stakeholders outside the supply chain that are mentioned in corporate reports

Changing based on stakeholders (C)

C1 Extent of supply chain changes based on stakeholder pressures

- Adoption of new quality standard in the supply chain

C2 Extent of organizational changes based on stakeholder pressures

- Human resource management

- Adoption of new internal procedures
Scale

Likert scale from 1 to 5 based on semantics of set of stakeholder documents/year

I3.1 Financial investments: Likert scale from 1 to 5 ( $1=$ no investment, $2=$ co-financing/small amount, $3=$ co-financing/medium amount, $4=$ co-financing/ large amount, $5=$ sole financer/large amount)

I3.2 Total number of cross-sector partnerships/year

I3.3 Total number of multi-stakeholder initiatives (subset of I3.2)

$$
\begin{aligned}
& 3=\text { Founder } \\
& 2=\text { Co-founder } \\
& 1=\text { Member/entrant }
\end{aligned}
$$

Likert scale from 1 to 5 based on semantics of set of global corporate reports/year

I5.1 Involvement in decision-making $(1=$ not in involved in decisions at all, $5=$ extremely involved in decisions)

I5.2 Frequency of involvement $(1=$ ad hoc involvement, 2 = irregular/infrequent, 3 = regular/ infrequent, $4=$ regular/rather frequent, $5=$ constantly involved)

I5.3 Geographical scope $(1=$ local, $2=\mathrm{regional} /$ national but decisive, $3=$ national, $4=$ regional across countries, $5=$ global)

L1.1 Likert scale from 1 to 5 based on semantics of set of global corporate reports/year

L1.2 Number of issues, topics, practices, principles mentioned

Likert scale from 1 to 5 based on semantics of set of global corporate reports/year

Likert scale from 1 to 5 based on semantics of set of stakeholder documents/year

Likert scale from 1 to 5 based on semantics of set of global corporate reports/year

C1.1 Depth

C1.2 Breadth

Likert scale from 1 to 5 based on semantics of set of global corporate reports/year

C2.1 Depth

C2.2 Breadth
Corporate report

CSR/sustainability report

Source(s)

Reports, press releases, official documents (External validation)

Based on partnership and/or company website

Based on partnership and/or company website

Based on partnership and/or company website

Corporate report

CSR/sustainability report

Reports, press releases, official documents (External validation)

Corporate report

CSR/sustainability report

Corporate report

CSR/sustainability report 
Table 8 continued

\begin{tabular}{lll}
\hline Measurement & Scale & Source(s) \\
\hline $\begin{array}{l}\text { C3 Extent to codification and formalization of } \\
\text { sustainability practices and principles generated } \\
\text { through stakeholder alliances and partnerships }\end{array}$ & $\begin{array}{l}\text { Number of documents mentioning best practices with } \\
\text { stakeholders }\end{array}$ & Corporate report \\
& C3.1 In set of global corporate reports/year & CSR/sustainability report \\
& C3.2 In company website/year & C3.3 Search engine with key words/year \\
C4 Assessment of changing capabilities by reports, & Likert scale from 1 to 5 based on semantics of set of & Reports, press releases, \\
press releases, official documents of stakeholders & stakeholder documents/year & (External validation) \\
outside the supply chain that are mentioned in & & \\
corporate reports & & \\
\hline
\end{tabular}

\section{References}

Ansell, C., \& Gash, A. (2008). Collaborative governance in theory and practice. Journal of Public Administration Research and Theory, 18, 543-571.

Argyris, C. (1977). Double loop learning in organizations. Harvard Business Review, 55, 115-125.

Armitage, D., Berkes, F., Dale, A., Kocho-Schellenberg, E., \& Patton, E. (2011). Co-management and the co-production of knowledge: Learning to adapt in Canada's Arctic. Global Environmental Change, 21, 995-1004.

Arts, B. (2002). 'Green Alliances' of business and NGOs. New styles of self-regulation or 'Dead-End Roads'? Corporate Social Responsibility and Environmental Management, 9, 26-36.

Austin, J. E. (2000). Strategic collaboration between nonprofits and business. Nonprofit and Voluntary Sector Quarterly, 29, 69-97.

Austin, J. E., \& Seitanidi, M. M. (2012). Collaborative value creation a review of partnering between nonprofits and businesses: Part I. Value creation spectrum and collaboration stages. Nonprofit and Voluntary Sector Quarterly, 41, 726-758.

Barney, J. (1991). Firm resources and sustained competitive advantage. Journal of Management, 17, 99-120.

Batie, S. (2008). Wicked problems and applied economics. American Journal of Agricultural Economics, 90, 1176-1191.

Berman, S. L., Wicks, A. C., Kotha, S., \& Jones, T. M. (1999). Does stakeholder orientation matter? The relationship between stakeholder management models and firm financial performance. The Academy of Management Journal, 42, 488-506.

Biermann, F., Chan, M.-s., Mert, A., \& Pattberg, P. (2007). Multistakeholder partnerships for sustainable development: Does the promise hold? In P. Glasbergen, F. Biermann, \& A. P. J. Mol (Eds.), Partnerships, governance and sustainable development. Reflections on theory and practice (pp. 239-260). Cheltenham: Edward Elgar.

Bitzer, V. (2012). Partnering for change in chains: The capacity of partnerships to promote sustainable change in global agrifood chains? International Food and Agribusiness Management Review, 15(B), 13-38.

Clarke, S., \& Roome, N. (1999). Sustainable business: Learningaction networks as organizational assets. Business Strategy and the Environment, 8, 296-310.

Clarkson, M. B. E. (1995). A stakeholder framework for analyzing and evaluating corporate social performance. Academy of Management Review, 20, 92-117.

Cuppen, E. (2012). A quasi-experimental evaluation of learning in a stakeholder dialogue on bio-energy. Research Policy, 41, 624-637.
Dahan, N. M., Doh, J. P., \& Teegen, H. (2010). Role of nongovernmental organizations in the business-government-society interface: Introductory essay by guest editors. Business and Society, 49, 567-569.

Dentoni, D., Blok, V., Lans, T., \& Wesselink, R. (2012a). Developing human capital for agri-food firms' multi-stakeholder interactions. International Food and Agribusiness Management Review, 15(A), 61-68.

Dentoni, D., Hospes, O., \& Ross, B. (2012b). Managing wicked problems in agribusiness: The role of multi-stakeholder engagements in value creation. International Food and Agribusiness Management Review, 15(B), 1-12.

Dentoni, D., \& Peterson, H. C. (2011). Multi-stakeholder sustainability alliances in agri-food chains: A framework for multidisciplinary research. International Food and Agribusiness Management Review, 14, 83-108.

Dierickx, I., \& Cool, K. (1989). Asset stock accumulation and sustainability of competitive advantage. Management Science, $35,1504-1511$.

Donaldson, T., \& Preston, L. E. (1995). The stakeholder theory of the corporation: Concepts, evidence, and implications. Academy of Management Review, 20, 65-91.

Duriau, V. J., Reger, R. K., \& Pfarrer, M. D. (2007). A content analysis of the content analysis literature in organization studies: Research themes, data sources, and methodological refinements. Organizational Research Methods, 10, 5-34.

Ferrell, O. C., Gonzalez-Padron, T. L., Hult, G. T. M., \& Maignan, I. (2010). From market orientation to stakeholder orientation. Journal of Public Policy and Marketing, 29, 93-96.

Fineman, S., \& Clarke, K. (1996). Green stakeholders: Industry interpretations and response. Journal of Management Studies, $33,715-730$.

Fisher, R. J. (1993). Social desirability bias and the validity of indirect questioning. Journal of Consumer Research, 20, 303-315.

Freeman, R. E. (2010). Strategic management: A stakeholder approach. Cambridge, MA: Cambridge University Press.

Glasbergen, P. (2007). Setting the scene: The partnership paradigm in the making. In P. Glasbergen, F. Biermann, \& A. P. J. Mol (Eds.), Partnerships, governance and sustainable development. Reflections on theory and practice (pp. 1-28). Cheltenham: Edward Elgar.

Glasbergen, P. (2010). Global action networks: Agents for collective action. Global Environmental Change, 20, 130-141.

Glasbergen, P. (2011). Understanding partnerships for sustainable development analytically: The ladder of partnership activity as a methodological tool. Environmental Policy and Governance, 21, $1-13$. 
Glaser, B. G., \& Strauss, A. L. (1967). The discovery of grounded theory: Strategies for qualitative research. London: Wiedenfeld and Nicholson.

Gray, B. (1989). Collaborating: Finding common ground for multiparty problems. San Francisco: Jossey-Bass Publishers.

Gulati, R. (1999). Network location and learning: The influence of network resources and firm capabilities on alliance formation. Strategic Management Journal, 20, 397-420.

Helfat, C. E., Finkelstein, S., Mitchell, W., Peteraf, M. A., Singh, H., Teece, D. J., \& Winter, S. G. (2007). Dynamic capabilities: Understanding strategic change in organizations. Oxford: Blackwell Publishing.

Hospes, O., van der Valk, O., \& van der Mheen-Sluijer, J. (2012). Parallel development of five partnerships to promote sustainable soy in Brazil: Solution or part of wicked problems? International Food and Agribusiness Management Review, 15(B), 39-62.

Hult, G. T. M. (2011). Toward a theory of the boundary-spanning marketing organization and insights from 31 organization theories. Journal of the Academy of Marketing Science, 39, 509-536.

Huxham, C. (1993). Collaborative capability: An intra-organizational perspective on collaborative advantage. Public Money and Management, 12, 21-28.

Jawahar, I. M., \& McLaughlin, G. L. (2001). Toward a descriptive theory of stakeholder theory: An organizational life-cycle approach. Academy of Management Journal, 26, 397-414.

Jones, T. M., Felps, W., \& Bigley, G. A. (2007). Ethical theory and stakeholder related decisions: The role of stakeholder culture. Academy of Management Journal, 32, 137-155.

Kale, P., \& Singh, H. (2009). Managing strategic alliances: What do we know now, and where do we go from here? Academy of Management Perspectives, 23(3), 45-62.

Kolk, A., Van Tulder, R., \& Kostwinder, E. (2008). Business and partnerships for development. European Management Journal, 26, 262-273.

Laplume, A. O., Sonpar, K., \& Reginald, A. L. (2008). Stakeholder theory: Reviewing a theory that moves us. Journal of Management, 34, 1152-1189.

Lawrence, A. T. (2002). The drivers of stakeholder engagement: Reflections on the case of Royal Dutch/Shell. Journal of Corporate Citizenship, 6, 71-85.

Le Ber, M. J., \& Branzei, O. (2010a). (Re)forming strategic crosssector partnerships: Relational processes of social innovation. Business and Society, 49, 140-172.

Le Ber, M. J., \& Branzei, O. (2010b). Value frame fusion in cross sector interactions. Journal of Business Ethics, 94, 163-195.

Levin, K., Cashore, B., Bernstein, S., \& Auld, G. (2012). Overcoming the tragedy of super wicked problems: Constraining our future selves to ameliorate global climate change. Policy Sciences, 45(2), 1-30.

Lund-Thomsen, P. (2009). Assessing the impact of public-private partnerships in the global south: The case of the Kasur Tanneries Pollution Control Project. Journal of Business Ethics, 90, 57-78.

Maak, T. (2007). Responsible leadership, stakeholder engagement, and the emergence of social capital. Journal of Business Ethics, 74, 329-343.

Maignan, I., \& Ferrell, O. C. (2004). Corporate social responsibility and marketing: An integrative framework. Journal of the Academy of Marketing Science, 32, 3-19.

Mandarano, L., \& Paulsen, K. (2011). Governance capacity in collaborative watershed partnerships: Evidence from the Philadelphia region. Journal of Environmental Planning and Management, 54, 1293-1313.

Mitchell, R. K., Agle, B. R., \& Wood, D. J. (1997). Toward a theory of stakeholder identification and salience: Defining the principle of who and what really counts. Academy of Management Review, 22, 853-886.

Murphy, M., Perrot, F., \& Rivera-Santos, M. (2012). New perspectives on learning and innovation in cross-sector collaborations. Journal of Business Research, 65, 1700-1709.

Penrose, E. (1959). The theory of the growth of the firm. New York: Wiley.

Pesqueira, L., \& Verburg, J. (2012). NGO-business interaction for social change: Insights from Oxfam's private sector programme. International Food and Agribusiness Management Review, 15(B), 133-138.

Peteraf, M. A. (1993). The cornerstones of competitive advantage: A resource-based view. Strategic management journal, 14(3), 179-191.

Porter, M. E., \& Kramer, M. R. (2011). Creating Shared Value How to reinvent capitalism-And unleash a wave of innovation and growth. Harvard Business Review, 89, 62-77.

Prahalad, C. K., \& Ramaswamy, V. (2004). Co-creating unique value with customers. Strategy and Leadership, 32, 4-9.

Rittel, H. W. J., \& Webber, M. M. (1973). Dilemmas in a general theory of planning. Policy Sciences, 4, 155-169.

Robinson, L. W., \& Berkes, F. (2011). Multi-level participation for building adaptive capacity: Formal agency-community interactions in northern Kenya. Global Environmental Change, 21, $1185-1194$.

Roloff, J. (2008). Learning from multi-stakeholder networks: Issuefocussed stakeholder management. Journal of Business Ethics, $82,233-250$.

Rondinelli, D. A., \& London, T. (2003). How corporations and environmental groups cooperate: Assessing cross-sector alliances and collaborations. Academy of Management Executive, 17, 61-76.

Scherer, A. G., Palazzo, G., \& Seidl, D. (2013). Managing legitimacy in complex and heterogenous environments: Sustainable development in a globalized world. Journal of Management Studies, 50(2), 259-284.

Schreyögg, G., \& Sydow, J. (2010). Organizing for fluidity? Dilemmas of organizational forms. Organization Science, 21, 1251-1262.

Seitanidi, M. M. (2010). The politics of partnerships: A critical examination of nonprofit-business partnerships. Dordrecht: Springer.

Seitanidi, M. M., Koufopoulos, D. N., \& Palmer, P. (2010). Partnership formation for change: Indicators for transformative potential in cross sector social partnerships. Journal of Business Ethics, 94, 139-161.

Seitanidi, M. M., \& Ryan, A. (2007). A critical review of forms of corporate community involvement: From philanthropy to partnerships. International Journal of Nonprofit and Voluntary Sector Marketing, 12, 247-266.

Selsky, J. W., \& Parker, B. (2005). Cross-sector partnerships to address social issues: Challenges to theory and practice. Journal of Management, 31, 849-873.

Selsky, J. W., \& Parker, B. (2010). Platforms for cross-sector social partnerships: Prospective sensemaking devices for social benefit. Journal of Business Ethics, 94, 21-37.

Strauss, A. L., \& Corbin, J. (1994). Grounded theory methodology: An overview. In N. K. Denzin \& Y. A. Lincoln (Eds.), Handbook of qualitative research (pp. 273-285). Thousand Oaks, CA: Sage Publications.

Suddaby, R. (2006). From the editors: What grounded theory is not. Academy of Management Journal, 49(4), 633-642.

Teece, D. J. (2007). Explicating dynamic capabilities: The nature and microfoundations of (sustainable) enterprise performance. Strategic Management Journal, 28, 1319-1350. 
Teece, D. J., Pisano, G., \& Shuen, A. (1997). Dynamic capabilities and strategic management. Strategic Management Journal, 18, 509-533.

Teegen, H., Doh, J. P., \& Vachani, S. (2004). The importance of nongovernmental organizations (NGOs) in global governance and value creation: An international business research agenda. Journal of International Business Studies, 35, 463-483.

Van Tulder, R. (2012). Sustainable development through strategic partnerships. In Paper presented at the 3rd international symposium on cross sector social interactions, 24-25 May. Rotterdam: University of Erasmus.

Verona, G., \& Zollo, M. (2011). Understanding the human side of dynamic capabilities: A holistic model. In M. Easterby-Smith \& M. A. Lyles (Eds.), Handbook of organizational learning and management (2nd ed.). Chichester: Wiley.

Vurro, C., Dacin, M. T., \& Perrini, F. (2010). Institutional antecedents of partnering for social change: How institutional logics shape cross-sector social partnerships. Journal of Business Ethics, 94, $39-53$.

Waddell, S. (2000). Complementary resources: The win-win rationale for partnerships with NGOs. In J. Bendell (Ed.), Terms for endearment: Business, NGOs and sustainable development (pp. 193-206). Sheffield: Greenleaf Publishing.

Waddell, S. (2002). Core competences a key force in businessgovernment-civil society collaborations. Journal of Corporate Citizenship, 7, 43-56.

Waddock, S. (2012). Difference making in a world of collapsing boundaries. In Paper presented at the 3rd international symposium on cross sector social interactions, 24-25 May. Rotterdam: University of Erasmus.

Weber, E. P., \& Khademian, A. M. (2008). Wicked problems, knowledge challenges, and collaborative capacity builders in network settings. Public Administration Review, 68, 334-349.

Wernerfelt, B. (1984). A resource-based view of the firm. Strategic Management Journal, 5, 171-180.

Winter, S. G. (2003). Understanding dynamic capabilities. Strategic Management Journal, 24, 991-995.

Yau, O. H. M., Chow, R. P. M., Sin, L. Y. M., Tse, A., Luk, C. L., \& Lee, J. S. K. (2007). Developing a scale for stakeholder orientation. European Journal of Marketing, 41, 1306-1327.

Yin, R. K. (2009). Case study research: Design and method. Newbury Park, CA: Sage Publications. 